\title{
CATEQUIZAÇÃO E PACIFICAÇÃO NA PROVÍNCIA DO AMAZONAS: AS VIAGENS DE ANTONIO DE MACEDO COSTA E JOÃO \\ BARBOSA RODRIGUES
}

IRMA RIZZINI ${ }^{1}$

Resumo: o objetivo do artigo é analisar a construção de conhecimento como alicerce para os projetos de intervenção social sobre os amazônidas, defendidos por duas autoridades que realizaram viagens pelos rios amazonenses. Os fins de suas missões consistiam na catequese e na civilização do homem amazônico, no caso do bispo D. Antonio de Macedo Costa (1884), e na pacificação de índios selvagens, conforme relato do diretor do Jardim Botânico do Amazonas, José Barbosa Rodrigues (1885). As obras dos viajantes são analisadas por meio do entrelaçamento de suas observações e interpretações sobre as populações locais com esquemas intelectuais, representações e formas de expressão histórica e culturalmente determinados.

Palavras-chave: catequese indígena; pacificação de índios; Província do Amazonas; D. Antonio de Macedo Costa; José Barbosa Rodrigues

\section{Catechization and pacification in the province of Amazonas: the journeys of Antonio de Macedo Costa and João Barbosa Rodrigues}

Abstract: the objective of this article is to analyze the construction of knowledge as a foundation for the social intervention projects on the Amazonians, defended by two authorities that made trips through the Amazonian rivers. The aims of his missions consisted in the catechesis and civilization of the Amazonian man, in the case of Bishop Antonio de Macedo Costa (1884), and in the pacification of wild Indians, according to the report of the director of the Botanical Garden of Amazonas, José Barbosa Rodrigues 1885). The travelers' works are analyzed through the interweaving of their observations and interpretations on the local populations with intellectual schemes, representations and forms of expression historically and culturally determined.

Keywords: indigenous catechesis; pacification of Indians; Province of Amazonas; D. Antonio de Macedo Costa; José Barbosa Rodrigues

Elevar, pois, o nível intelectual e moral dos povos do Amazonas é uma questão política, uma questão social, uma questão de humanidade, um grave problema no ponto de vista da civilisação e do Christianismo.

Entre as datas celebres da província do Amazonas deve figurar esta que symboliza paz entre os Crichanás e os civilisados, paz que restituiu á província um grande rio piscoso, extensas florestas ricas de productos vegetaes, um solo uberrimo e a tranquilidade de um povo (Costa, 1884, p. 6).

\footnotetext{
${ }^{1}$ Doutora em História Social pela Universidade Federal do Rio de Janeiro (UFRJ). Professora da Faculdade de Educação da UFRJ. E-mail: irma.rizzini@gmail.com
} 
Em meados da década de 1880, duas autoridades, uma eclesiástica e a outra pública, empreenderam viagens pelos rios amazonenses, comprometidos com a realização de tarefas específicas na Província. Eram homens que estavam a serviço da Igreja ou do Estado, os quais assumiram incumbências bastante concretas visando, em última análise, a conquista de uma população e/ou de um território. Os fins de suas missões consistiam na catequese e na civilização do homem amazônico, no caso do bispo D. Antonio de Macedo Costa (1884), e na pacificação de índios selvagens, de modo a permitir a expansão sobre territórios que ofereciam riscos aos colonos, conforme relato do diretor do Jardim Botânico do Amazonas, José Barbosa Rodrigues (1885). As obras de Macedo Costa, A Amazonia: meio de desenvolver a sua civilisação, 1884, e a de Barbosa Rodrigues, Pacificação dos Crichanás, 1885, de onde foram retirados os trechos acima, são analisadas sob a perspectiva proposta por João Pacheco Oliveira Filho em Os atalhos da magia: reflexões sobre o relato dos naturalistas viajantes na etnografia indígena (Oliveira Filho, 1980). Os relatos dos viajantes são compreendidos na articulação a certos esquemas intelectuais, representações e formas de expressão histórica e culturalmente determinados. O roteiro proposto por Oliveira Filho é pertinente nesse caso, já que os autores construíram seus discursos e planos de ação a partir de observações in loco, como o fizeram os naturalistas. Os viajantes apresentaram os resultados de seus empreendimentos em eventos públicos realizados na cidade de Manaus, entre 1883 e 1884, com relatos orais e exposições de artefatos indígenas, além da publicação de impressos.

Embora suas comissões não tivessem propósitos científicos como prioridade, os autores escreveram seus textos com base nas viagens realizadas por rios da Província do Amazonas - as viagens pastorais do bispo e as excursões de pacificação de índios do diretor do Museu Botânico. A análise dos relatos dos viajantes é guiada pelo relacionamento entre as seguintes instâncias: a) o ver, que consiste no registro primário dos acontecimentos reais, subordinado a certos esquemas intelectuais e certas regras que organizam os fatos observados, cujos conteúdos são orientados por "coordenadas precisas em termos históricos e culturais", constituindo assim, o perceber (b); c) o interpretar, determinado por conceitos e noções aplicados às observações, interligados a "um conjunto historicamente determinado de teorias e ideologias"; d) o expressar, transformando as impressões estruturadas em função de b) e c), em um discurso exte- 
riorizado, materializado dentro das "modalidades do discurso historicamente elaboradas e disponíveis" (Oliveira Filho, 1980, p. 7). Os meios de divulgação dos trabalhos dos viajantes foram a escrita (publicação) e a oral (conferência), além da exposição de objetos indígenas, no caso de Rodrigues. Os resultados de suas viagens foram expostos para um seleto público de autoridades públicas, intelectuais e membros de grupos econômicos da região. Por último, há que se considerar as finalidades práticas das viagens, que não só interferem ou até direcionam o desempenham das outras funções. A articulação das finalidades práticas das viagens com os seus registros/discursos é fundamental, pois suas missões visavam o planejamento de programas de catequese dos "povos" (Macedo Costa) e a pacificação e a civilização de índios (Barbosa Rodrigues).

Como inspiração para uma compreensão da "organização social das viagens", utilizamos o texto de Oliveira Filho (1987), Elementos para uma sociologia dos viajantes. Certamente não como roteiro de análise, por dois motivos: o primeiro, por não dispormos das informações necessárias a um adequado exame da organização das viagens, de acordo com o percurso proposto pelo autor; e segundo, por não nos propormos a realizar aqui um estudo exaustivo de como foram organizadas estas viagens, as lutas por prestígio, os jogos de poder, os financiamentos, os "ganhos" materiais e sociais posteriores, etc. Nosso propósito reside na análise das representações a respeito da população da região e tudo aquilo que diz respeito aos seus costumes, modos e meios de vida, os quais, por sua vez, orientam as propostas civilizatórias dos autores expressas em termos de propostas de educação da população ou meramente de sedentarização e incorporação aos meios de produção vigentes à época na região. No entanto, as informações disponíveis sobre aspectos que interferiram no planejamento, na realização e nos resultados das viagens são articuladas aos relatos dos autores. É importante chamar a atenção para o fato de que um dos autores não escreveu seu trabalho a partir de observações feitas em uma área específica - o bispo Antonio Macedo Costa elaborou o seu projeto civilizatório, baseado nas viagens pastorais que empreendeu pelas províncias do Amazonas e do Pará. Nas viagens de evangelização, o eclesiástico teve contato com os mais diversos grupos populacionais que habitavam a região, experiência manifestada em seu texto com a descrição dos grupos populacionais que viu e percebeu nesses encontros, mas que também confrontou com as representações produzidas por outras fontes. Já Barbosa Rodrigues fundamentou o seu rela- 
to com base em três excursões ao rio Jauapery de modo a contatar e negociar com os índios então denominados de Crichanás. ${ }^{2}$

É importante ressaltar que os autores não podem ser caracterizados como viajantes, no sentido atribuído às comitivas lideradas por estrangeiros que excursionaram na região entre os séculos XVIII e XIX. Macedo Costa e Barbosa Rodrigues se deslocaram para a região com a finalidade de cumprir missões específicas, que eventualmente exigiam a realização de viagens ao interior, percorrendo os rios da região. Ambos atuaram com o apoio governamental da província e/ou do Império. As excursões do pacificador eram custeadas pelo governo provincial e as viagens pastorais do bispo contaram com o apoio tanto do Ministério da Marinha, quanto da administração local, com a cessão de lanchas. Dada as relações entre a Igreja Católica e o Estado no período, não é possível tratar os projetos e as ações do representante da diocese como autônomos e destacados dos propósitos dos governos central e local.

O tema da civilização dos nativos é comum aos autores, sendo que Macedo Costa se detém na questão da transformação dos modos de vida da população pela via da evangelização, embora o tema perpasse o texto de Barbosa Rodrigues, que não se eximiu de propor meios de educar os índios para a vida civilizada. A análise dos projetos civilizatórios dirigidos aos "povos do Amazonas" (Costa, 1884, p. 6), por meio das ideias e dos planos defendidos pelos autores aqui retratados, não parte da premissa de que tais propostas estariam calcadas na busca por um alto grau de civilização e cultura, no sentido elisiano (Elias, 1994), mas sim, obedecendo a um recorte étnico e social - a participação da população local na vida social e econômica da província pela via do trabalho, como operários e camponeses, de forma disciplinada, no tempo e no espaço, aspectos supra valorizados pela retórica nos textos da época da decadência da agricultura e da persistência do nomadismo da população.

Oliveira Filho mostra que o ideal de uma Amazônia agrícola está presente em um grande número de autores de épocas diferentes, tendo sido criado um "padrão narrativo" (Oliveira Filho, 1979, p. 108). Entre o século XIX e as primeiras décadas do XX, o nomadismo dos grupos populacionais e a atividade extrativista eram denuncia-

\footnotetext{
${ }^{2}$ Os Crichanás correspondem à etnia Waimiri-Atroari, localizada no Amazonas e Roraima, sendo sua população estimada em 611 indivíduos pelo Censo de 1994 (Silva; Grupioni, 1995, p. 43).
} 
dos como impedimentos ao cultivo agrícola regular e sedentário. ${ }^{3}$ Já nos primórdios da criação da Província do Amazonas, o primeiro presidente ${ }^{4}$ manifestou sua preocupação com a "civilização das hordas numerosas" de índios e com o aumento do número de "braços" para a agricultura e serviços. São questões tratadas com destaque nos relatórios dos presidentes e vice-presidentes de província e frequentemente abordada por autoridades, tais como, diretores de índios, missionários e diretores de instrução pública. Tal preocupação gerou políticas que nortearam práticas de sujeição dos grupos indígenas, como a criação de missões para o aldeamento dos índios "dóceis" e a repressão aos grupos indígenas considerados "bravos", através de investidas da Guarda Nacional e de particulares.

Alfredo Wagner Almeida encontrou este padrão discursivo nos relatórios e falas de presidentes e vice-presidentes da Província do Maranhão, entre as décadas de 1840 e 1880 (Almeida, 1977). Os documentos apresentam copiosas informações concernentes ao que denominavam de "decadência da agricultura". A decadência é descrita segundo pressupostos similares, com um padrão de explicação que não deixa margem para outras representações sobre o tema. As "origens" da decadência são pensadas a partir de uma situação de "prosperidade" da agricultura, dita a "idade de ouro da lavoura" e a partir de uma série de "faltas" tidas como comprometedoras ao desenvolvimento da agricultura: falta de conhecimentos técnicos dos lavradores, de vias de comunicação adequadas para o escoamento da produção, de capitais/recursos para assegurar a manutenção e o desenvolvimento da agricultura e a falta de braços. As medidas para retomada do crescimento agrícola também gozavam de uma "obviedade e consensualidade", que, como observa Almeida, "torna-se desprezível aprofundar o seu sentido particular" (Almeida, 1977, p. 93). Assim, as propostas eram bastante genéricas: fundação de escolas agrícolas, emigração de colonos livres, construção de estradas e desobstrução das vias de navegação. No caso da Província do Amazonas, os obstáculos para o desenvolvimento da agricultura eram imputados, em parte, aos costumes da população de origem indígena, que teria gosto pela vida errante e nômade,

\footnotetext{
${ }^{3}$ A mobilidade dos grupos indígenas e dos trabalhadores dos seringais pode ser compreendida como resistência à sujeição. Barbara Weinstein chama a atenção para a mobilidade da população dedicada à extração do látex na Amazônia imperial e para o fato de os trabalhadores possuírem um certo grau de controle sobre as suas atividades (Weinstein, 1993, p. 29 e 39).

4 João Baptista de Figuereido Tenreiro Aranha, nomeado pelo Imperador em 07/06/1851. A província foi instalada em 01/01/1852.
} 
apenas satisfeita em suprir as suas necessidades naturais. As soluções propostas pelos mais diversos atores sociais - intelectuais, autoridades públicas e eclesiásticas - recaíram sobre a constituição de uma população útil, por meio da educação dos nativos ou pela importação de colonos (nacionais e estrangeiros).

Para Rodrigues, a atração pela borracha trouxe conseqüências negativas para os habitantes de Moura que se empregavam na "perniciosa industria da borracha", deixando abandonado o Jauapery que ia sendo apossado pelos Crichanás, fazendo com que se aproximassem das praias onde os moradores pescavam, e até do próprio povoado (Rodrigues, 1885, p. 9). A atividade de extração de produtos naturais era percebida como um empecilho à agricultura, explicado pelo fascínio que exercia sobre os homens, afastando-os do cultivo agrícola. Com a ascensão da exploração da borracha na província, a extração da seringa assumiu o lugar de vilão da decadência da agricultura e dos povoados, que perdiam a sua população útil para os seringais, a despeito do reconhecimento de sua importância para a receita local.

Para Oliveira Filho (1979, p. 121), a polêmica criada em torno da borracha não está relacionada a uma classificação dos produtos em "agrícolas" ou "espontâneos", mas sim à distinção entre "formas de produção contrastantes entre si", a saber, o seringal "caboclo" e o seringal "de apogeu". No início da exploração da borracha, o modelo era o mesmo das outras atividades extrativas ("caboclo"), mas no seu "apogeu", uma nova forma de organização da produção fora introduzida. Em praticamente todo o Segundo Reinado, o trabalho nos seringais foi realizado predominantemente pela população local, sendo que na fase do "rush" (1890-1912), a atividade atraiu enormes levas de nordestinos. Contudo, pondera Hideraldo Lima da Costa, não tendo sido desenvolvida nenhuma melhoria tecnológica para aumentar a produtividade, a cultura e os modos de vida dos regionais foram fundamentais para que os nordestinos recémchegados se tornassem seringueiros (Costa, 1995, p. 188).

Não é demais lembrar que a dedicação da população à extração de produtos naturais em detrimento do cultivo era uma representação de grupos dominantes da região, principalmente das autoridades do Estado. De acordo com Patrícia Sampaio, a população associava a atividade da extração com a agricultura de subsistência e comercial (Sampaio, 1997). A agricultura diversificada e em pequena escala da região foi freqüentemente interpretada como sem importância econômica frente à grande mo- 
nocultura implementada em outras províncias, como as do café, do açúcar e do algodão.

Diante desse quadro, intensificaram-se as comissões de estudos para a colonização da região, envolvendo a ocupação humana do grande vale. As propostas do bispo e do naturalista/pacificador, postas em debate no mesmo período, ora se confrontam, ora se conciliam, contudo, partem de um repertório aproximado de representações sobre a população da região, como veremos no decorrer deste texto.

\section{Dom Macedo Costa e o Christophoro}

Enviado à Europa com apoio financeiro do governo imperial e sob a tutela do paraense Romualdo Antonio de Seixas, Arcebispo da Bahia, para aprimorar seus estudos eclesiásticos, Dom Antonio de Macedo Costa (1830-1891) foi tonsurado em 1855 na Igreja Matriz em Paris e quatro anos depois formou-se em Direito Canônico no Liceu Pontifício de São Apolinário, em Roma. De volta à terra natal, em fins de 1859, dedicou-se ao magistério, tendo lecionado no Ginásio Baiano, dirigido pelo Barão de Macaúbas, e no Liceu de Salvador (Lustosa, 1939, p. 24). Designado Bispo do Pará em 1861, permaneceu no cargo até 1889. Na Amazônia, escreveu a maior parte de sua obra. De acordo, com Karla Martins, D. Macedo D. Macedo Costa era um homem erudito, conhecia muitos autores europeus, citados em seus artigos, como os publicados no jornal católico A Estrella do Norte (1863-1869) (Martins, 2015). Da cidade de Belém partia para as viagens pastorais ao Amazonas, tendo feito a sua primeira visita pastoral à imensa província em 1862, parte integrante de sua jurisdição. Dois anos depois, viajou pelo rio Solimões até Tabatinga. As viagens pastorais, associadas ao seu engajamento em prol do fortalecimento da Igreja Católica no país ${ }^{5}$, foram fontes de inspiração para a elaboração de projetos de catequese e educação do "homem amazônico", incluindo nessa categoria a "raça indígena modificada" que compunha o "fundo da

\footnotetext{
${ }^{5} \mathrm{O}$ bispo lutou, a partir de várias frentes, pela reforma do catolicismo no país, atento às questões internas à região e ao universo católico mais amplo. D. Macedo Costa e D. Vital, Bispo de Olinda, foram os protagonistas da famosa questão religiosa, em meados da década de 1870, quando proibiram as Comunidades Eclesiásticas de suas jurisdições de admitirem maçons, resultando na prisão de ambos na Fortaleza da Ilha das Cobras, no Rio de Janeiro, em 1874. Pouco tempo depois foram perdoados pelo Imperador (Bittencourt, 1969, p. 140; Martins, 2015). As desavenças resultaram no relato de Macedo Costa, A questão religiosa do Brazil perante a Santa Se, ou, a missão especial a Roma em 1873 a luz de documentos publicados e ineditos. Nova ed. com accrescimos e mais corr. Lisboa: Lallemant Freres, 1886.
} 
população do Amazonas". Aderindo à retórica da vida errante dessa população, o sacerdote defendia a sua regeneração pela educação cristã, a ser igualmente oferecida ao europeu que se embrenhava nas matas para comercializar com a população (o "comerciante regatão"), tomado pelos vícios que assolavam os habitantes do vale (Costa, 1884, p. 9).

O bispo participou diretamente de projetos culturais e educacionais de Belém e Manaus, discursando na inauguração de símbolos da civilização culta, como a Sociedade de Instrução Pública em Manaus (1871) e o teatro Nossa Senhora da Paz em Belém (1888). No Pará, criou um asilo para a educação de órfãs e um instituto de ensino profissional para meninos indígenas e desvalidos. Dirigiu pessoalmente a "regeneração" dos seminários da diocese para formar sacerdotes dedicados à educação dos meninos e à catequese dos indígenas. Atento ao ensino religioso nas escolas públicas da região, publicou e distribuiu pelas escolas livros sobre história bíblica e civilidade cristã, de sua autoria $^{6}$. D. Macedo Costa integrava diferentes círculos de debates sobre a construção da sociedade brasileira, tendo se associado ao Instituto Histórico e Geográfico Brasileiro em 1878 (Martins, 2005, p. 11). Seus escritos trazem indícios de um homem conectado às discussões sobre a identidade nacional articulada às características culturais locais. Propunha reformas sociais e educacionais, atento ao movimento de valorização da vida local, quando propôs no discurso de inauguração da Biblioteca Pública do Pará a criação de um museu para a admiração dos produtos das regiões do Amazonas, e também de uma escola normal, de modo a

[...] promover a verdadeira reforma da instrucção, pela regeneração do professorado, pela prática dos verdadeiros methodos, mas sobretudo, pela união da instrucção com a educação, pela união da educação com a Religião, que é o aroma que embalsama a sciencia, e a impede de corromper-se (Costa, 1978, p. 16).

A associação entre instrução, educação, ciência e religião pressupunha ultrapassar o plano dos discursos: entre outras ações, o bispo partiu para a execução de um de seus planos de catequese e instrução com a criação de um internato cuja finalidade era educar meninos indígenas "das selvas" e meninos pobres dos povoados e das capi-

\footnotetext{
${ }^{6}$ Os dados biográficos apresentados baseiam-se nas obras de Bittencourt (1969) e Lustosa (1939). As iniciativas educacionais descritas baseiam-se em artigos e notícias dos jornais A Boa Nova (da diocese), A Constituição e A Província do Pará. A respeito de seus projetos para a Amazônia, ver: Martins, 2001; e Martins, 2005.
} 
tais das Províncias do Pará e do Amazonas, preparando-os para o exercício de ofícios mecânicos e de atividades agrícolas. Segundo, José Ricardo de Almeida, o bispo percorreu várias províncias, recolhendo donativos para a "obra civilizadora projetada", instalada em vasta área, de floresta virgem, a 12 quilômetros da cidade de Belém, no ano de 1882. No começo, havia 60 alunos, "quase todos trazidos das regiões mais distantes de sua diocese, que o prelado tinha percorrido nas suas viagens pastorais", alçando 100 internos em 1889 (Almeida, 1989, p. 270). Os estudos consistiam em leitura, escrita, desenho, música, aritmética, instrução cívica (direitos e deveres do cidadão), doutrina cristã; ensino de ofícios como os de forjador, limador, fundidor, carpinteiro, marceneiro, pedreiro, sapateiro, alfaiate, etc. Havia uma tipografia, o ensino agrícola e uma fábrica de farinha de mandioca para consumo dos alunos e venda do excedente. As despesas eram cobertas por contribuições particulares e uma parcela menor vinha do Governo Imperial e dos governos do Pará e do Amazonas (Rizzini, 2004).

No mesmo período da criação do internato, Macedo Costa elaborou um projeto mais amplo de catequese da população do interior, principalmente daquela embrenhada nos seringais, avaliados por algumas vozes como perniciosos à economia e aos homens da província, levando ao abandono da agricultura e da indústria, no primeiro caso, e à grande "laxidão dos costumes" e "dissolução dos vinculos da familia", "sequellas inevitáveis deste viver incerto e vagabundo" (Costa, 1884, p. 10). Ressalta-se que o projeto não se restringiu à catequese, tendo sido adaptado, segundo Bittencourt, à instrução de crianças de lugares do interior, onde houvesse pelo menos trinta crianças em idade escolar (Bittencourt, 1969, p. 140). O “Christóphoro", "navio-Igreja” que levaria missionários para a educação religiosa, se encarregaria também da educação secular. Somente o internato recebeu apoio para a sua instalação; os outros planos encontraram descrença e resistências.

O projeto pedagógico do principal representante da diocese paraense estava baseado nos fatores que os homens ilustrados do século XIX elegeram como determinantes para se alcançar a civilização. Estes "elementos essenciais" assim foram descritos por Macedo Costa na conferência dirigida a "um grande número de pessoas gradas" no paço da Assembléia Provincial do Amazonas, em 1883:

Senhores, não póde a civilisação existir e desenvolver-se sem certo 
adminiculos que são, por assim dizer, os seus factores. Apego ao solo e á propriedade, lavoura sedentária, uma boa organização da família e do trabalho, um lar com suas tradições venerandas transmittindose de pais a filhos, boa administração da justiça, a religião com as sublimes emoções de suas festas [...], a escola onde irradiou-se na nossa intelligencia a alvorada rumorosa das lettras, eis ahi outros tantos elementos essenciaes, cuja açcão combinada dá, como resultante, a civilisação de um povo (Costa, 1884, p. 11).

Portanto, diferente de Barbosa Rodrigues, que escreveu seu texto baseado em comissões específicas, Macedo da Costa apresentou, segundo suas palavras, um "projecto", que tinha por objetivo "melhorar o estado presente da população do Amazonas". O projeto, defendido frente às elites locais, recebeu contestações que o autor rebateu uma a uma, na edição de $1884 .^{7}$ A "evangelização do grande valle" foi o meio proposto para alcançar o objetivo da civilização do homem amazônico. O projeto dividia-se em três partes ("para proceder com methodo"), que correspondiam a:

$1^{\circ}$ - Um diagnóstico da população da região: o "homem Amazonico" "sua situação atual e necessidade de um prompto remedio"; $2^{\circ}$ - Uma metodologia de ação - "o plano de um vapor Igreja, de um Templo fluctuante, destinado á evangelização do grande Valle".

$3^{\circ}$ - Uma justificativa para a sua execução - a necessidade, as vantagens, os "proveitos espirituais e temporais", e a exequibilidade do projeto (Costa, 1884, p. 8).

O foco de Macedo Costa dirigia-se ao "povo amazonense", à "classe trabalhadora", e não à "gentilidade que erra ainda completamente selvagem no meio de nossos bosques seculares". Embora preconizasse que tribos numerosas deveriam entrar na "nossa comunhão social", pois "em pleno XIX seculo, [estão] assentadas á sombra da morte", ele centrou o seu plano na recuperação das "populações christãs", degradadas com a vida que levavam na região, especialmente nos seringais (Costa, 1884, p. 17).

Portanto, ele estava lidando com três grupos raciais, segundo as representações correntes sobre a população amazônica: o índio genérico (o tapuio),

Compõe-se o fundo da população do Amazonas da raça indígena, pu-

\footnotetext{
${ }^{7}$ Texto publicado no Rio de Janeiro, em 1884, após a conferência sobre o "meio de desenvolver a civilisação" da Amazônia, recitada em Manaus, no Paço da Assembleia Provincial, perante o Exmo Sr. Presidente da Provincia e grande número de pessoas gradas, no dia 21/03/1883. Há uma edição de 1882, publicada em Manaus.
} 
ra já modificada, mas conservando, máu grado seus defeitos, as qualidades de seu typo. Docil, intelligente, mansa, sobria, capaz de supportar as maiores privações e fadigas: tal o caracter desta raça, que, com ser instruida e educada muitissimo imperfeitamente, ahi está já offerecendo um elemento util ao trabalho nacional (Costa, 1884, p. 8).

O mameluco, uma raça que surge no período colonial e "que se distinguia das hordas selvaticas pela côr e pela applicação á agricultura e ás artes fabris, cujas manufacturas primorosas attestavam o estado de sua industria e civilisação". O europeu, que também se degenera e mesmo tendo sido instruído na religião desde a mais tenra infância, sente o "espírito uma pasmosa debilidade, si casualmente nos achamos em logares desprovidos destes socorros", a saber: os sacramentos, leitura de bons livros, práticas de ministros eclesiásticos, exemplos de pessoas virtuosas e outros subsídios. Concordando com a "opinião dos homens competentes" de sua época, Macedo Costa condicionou o habitat natural à raça, afirmando que "a raça europeia não pode impunemente afrontar os charcos, as exhalações miasmaticas d'aquellas solidões em que medra a sinphonia elastica; em geral para nossas industrias extractivas precisamos do braço indigena". O melhor colono do Amazonas é o seu povo (Costa, 1884, p. 9-18).

Em um momento do seu texto, Macedo Costa cita obstáculos de ordem política e econômica para o "melhoramento moral, religioso, social" no seio do Amazonas, mas o seu discurso imediatamente recai sobre o "caracter indio". Assim, aspectos como a "pressão despotica das autoridades locais, politicagem" associados aos "lucros deslumbrantes das novas drogas (quase sem trabalho)" juntam-se a qualidades vistas como da natureza do índio: a "tendencia ingenita do caracter indio para uma vida vaga, aventurosa e solta de toda sujeição" (Costa, 1884, p. 13).

Desta forma, como meio de mudar os costumes desse "povo abandonado a si proprio, entregue a largos ocios e excessos bacchanaes, sem nenhuma instrução nem civil nem religiosa", ele propôs o plano de um vapor Igreja, sonhando para o Amazonas um "porvir grandioso que todos queremos" (Costa, 1884, p. 18). O Navio-Igreja, Basílica-naval, Navio-missionário, enfim o Christophoro, "portador de Christo", se contrapõe ao antigo sistema de missões, estabelecidas em pontos fixos com uma população reunida por descimentos. O navio a vapor iria ao encontro das "populações christãs e pagãs que hoje vivem e morrem completamente ao desamparo", navegando 
pela "imensa rede fluvial do rio-mar, levando as luzes e os soccorros de espirito" aos seus habitantes (Costa, 1884, p. 21). Costa argumentava que a evangelização do vale deveria estar adaptada à sua geografia: o Amazonas dispunha de um sistema hidrográfico "por onde póde passar o Evangelho", da mesma forma como passavam os armazéns flutuantes dos comerciantes (Costa, 1884, p. 30).

O Christophoro também beneficiaria os religiosos da diocese ao mantê-los reunidos, contra o perigo de afogar-se no mercantilismo e naufragar na fé. Com isso, o bispo esperava reanimar a obra evangelizadora dos jesuítas, que em sua opinião fora despoticamente interrompida pelo Marquês de Pombal, propondo a sua integração à nação:

Se lhes fosse dado continuar seus evangelicos labores, hoje provavelmente, não tiveramos mais um só indio selvagem nas nossas florestas; lograramos a doce consolação de ver todas as tribus caminhando animosas para um illuminado porvir, incorporadas á comunhão politica do imperio, mesmo aquellas que por seus instintos ferozes incutem terror ao homem civilizado (Costa, 1884, p. 25).

Neste ponto do texto, ele agrega os "indigenas ainda selvagens" ao seu projeto, propondo aprender-lhes as gírias, formar catequistas e intérpretes, "estender cuidados assiduos e inteligentes a essas miseras hordas". Adotando um discurso salvacionista, o sacerdote propunha aprofundar-se o conhecimento sobre os grupos indígenas para a salvação da raça, mas não de culturas vistas como bárbaras e resistentes à sujeição.

Não, não passará muito tempo sem que sôe para esta pobre raça proscripta a hora da redempção! Basta já tresentos annos de barbarie para ella, de vergonha para nós! O seculo XX não achará mais no mesmo estado horrendo e lastimoso em que agora a vemos! (Costa, 1884, p. 41)

No rol das vantagens temporais do projeto, como a política e a comercial, incluía-se também a científica, a ser desenvolvida por "sacerdotes com pendor para os belos estudos", nos intervalos dos trabalhos apostólicos. Estes realizariam pesquisas de interesse para a província, na área das ciências naturais, a saber: flora, questões topográficas e etnográficas, meteorologia, arqueologia, geologia e medicina (Costa, 
1884, p. 43).

O Estado seria o grande beneficiado pelo empreendimento, segundo a retórica corrente do aproveitamento do braço indígena para a produção local. Os poderes públicos estariam investindo na formação de um povo trabalhador e ordeiro. Costa juntou-se às vozes que defendiam a bandeira da diminuição da mortalidade da população pela aquisição de hábitos regulares de vida e do fim do extermínio de índios. Para o autor, o Brasil, uma "nação generosa e catholica", não podia adotar o ideal norteamericano de "levantar o edificio da prosperidade nacional sobre a sepultura de uma raça" (Costa, 1884, p. 43). Tratava-se, portanto, de um projeto que deveria interessar aos poderes públicos, local e central, e aos habitantes da província: capitalistas, negociantes, industriais, lavradores, empregados públicos, patrões e empregados dos seringais.

A viabilidade do projeto defendida por seu autor não parece ter convencido os grupos sociais acima listados. O presidente da província, José Paranaguá, comentou em seu relatório do ano de 1882 que a ideia da construção "de uma sumptuosa basilica fluctuante, o Christophoro, destinado a levar a fé e a civilisação por toda a parte onde se encontrar uma aldêa, uma maloca de indios" fascinava (Paranaguá, 1883, p. 45). Entretanto, os seus possíveis resultados não convenceram o dirigente, pois não queria sacrificar a proposta de construir pequenos asilos próximos aos aldeamentos e povoações, para o ensino de ofícios a "orphãos e menores indigenas", sugestão reforçada pelo visitador escolar, Joaquim Azambuja, no relatório apresentado ao governo da província após a inspeção escolar realizada em 1883 em alguns municípios do Amazonas (AZAMBUJA, s.d. [1884]). Vale lembrar que o bispo expôs suas ideias reformadoras para um governo liberal, tendo enfrentado muitos conflitos com os liberais no Pará, especialmente os maçons. ${ }^{8}$

Ao final do texto, em carta sem destinatário explicitado, Macedo da Costa listou oito contestações feitas ao seu projeto, respondendo a cada uma, amparado na sua "experiência de quase vinte anos 20 anos percorrendo os centros do Pará e do Amazonas" (Costa, 1884, p. 73). Os obstáculos financeiros constituíam a primeira difi-

\footnotetext{
${ }^{8}$ No Pará Oitocentista, o termo ultramontano era utilizado por liberais como sinônimo de atraso, para designar os padres, como D. Macedo Costa, comprometidos com a infalibilidade papal, decretada pelo Concílio Vaticano I, e a intervenção da Igreja em assuntos sociais. Segundo Karla Martins (2005, p. 8), o bispo evitava o termo em seus escritos devido ao caráter pejorativo que assumiu.
} 
culdade, ao que o bispo argumentou terem os seringueiros muito dinheiro e que o governo da província não tinha como gastar em obras públicas os valores acumulados em seu tesouro, por falta de operários. Havia dinheiro para um teatro, um mercado de ferro, para pontes pênseis, jardins, afirmou o bispo. Outras críticas referiam-se à dispersão dos povos, que seria acentuada pelo Christophoro, e ao descontentamento dos patrões pelo afastamento temporário dos seus operários do trabalho. Ele procurou combater o temor da dispersão da população, fazendo crer que os encontros promovidos pelo serviço religioso em certos pontos (e não de barraca em barraca), incitariam no povo o "gosto da sociabilidade", levando à criação de prósperos povoados (Costa, 1884, p. 66). Na defesa apaixonada pela vida civilizada, dentro dos cânones da moral cristã, o bispo "ignorava" o esquema de funcionamento dos seringais, que tornava o trabalhador dependente ao patrão, pelas dívidas contraídas na barraca. Porém, logo adiante ele tratou das vantagens que os patrões poderiam usufruir com o projeto, meio eficaz de combate aos costumes dos trabalhadores e às suas artimanhas frente à exploração do seu trabalho:

O que perturba o trabalho [...] é a orgia, são as noites passadas em claro nos bachanaes, nos desmanchos dos costumes, são os habitos da ociosidade e da embriaguez, são as deserções para eximir-se ao pagamento das dívidas (Costa, 1884, p. 70).

Nas visitas pastorais pelo Madeira, Purús e outros rios, o bispo contava com a colaboração dos patrões, os quais convocavam seus operários e os deixavam ouvir as prédicas e receber os sacramentos - "há muitos pedidos para que um Padre faça uma visita no tempo do fabrico da borracha". As crianças seriam beneficiadas com bons exemplos dos pais para os filhos. Mas alerta,

[...] se os pais os acostumam desde pequenos á embriaguez; se os deixam corromper-se nas dansas lascivas [...] tornam-se uns vadios, uns devassos, uns insolentes, uns ingratos e pior, não ajudarão os pais na velhice - a miseria entra pela porta a dentro com todo o seu cortejo de horrores (Costa, 1884, p. 71).

Uma das contestações contrapôs o projeto religioso ao governamental, defendendo a fundação no interior de estabelecimentos de educandos artífices. Já existia em Manaus, desde 1858, uma Casa de Educandos Artífices, que tinha por finalidade o 
ensino de primeiras letras, música e ofícios a "meninos desvalidos", entre os quais indígenas, pelo sistema de internato (Alves, 1995; e Rizzini, 2006, p. 133-171). Neste ponto, o bispo recorreu a argumentos alinhados às preocupações das autoridades e intelectuais da região com a situação das crianças pobres e indígenas, lembrando que era preciso adotar diferentes estratégias para a reforma social, pois "cada uma fica com seu merito e sua necessidade". A Casa de Educandos só educava os meninos mas e a família? E a grande massa do povo? Outra dificuldade era a de pessoal - não havia sacerdotes e nem homens seculares instruídos e virtuosos, dispostos a largar a comodidade da cidade para viver em lugares longínquos "para se desvellarem na educação, na instrucção de tappuyosinhos boçaes, cerrados, grosseiros". Bem mais fácil era achar em quantidade "especuladores que os vão reduzir a captiveiro, que os deixem vegetar na estupidez". Em defesa do alargamento das ações da diocese, o bispo denunciou a exploração do trabalho dos filhos dos índios e criticou a cultura política local, que deixava os estabelecimentos educacionais sujeitos às oscilações da política, quando "um presidente os cria; outro presidente os supprime" (Costa, 1884, p. 67-68).

E conclui solene: O Christianismo é o principio regenerador, é o elemento civilisador por excellencia (Costa, 1884, p. 68). Nas disputas entre a Igreja e o Estado, manifestadas pelas querelas entre a autoridade religiosa e grupos políticos locais, estava em jogo a própria representação de catequese, quando catequizar índios não era entendido como uma premissa e um monopólio dos homens da Igreja, conforme verificaremos com o exemplo das ações de catequese do governo da província e dos moradores do povoado de Moura, relatadas por Barbosa Rodrigues.

Os povos do Amazonas não puderam contar com o "porvir grandioso" prometido por Macedo Costa, mas sem dúvida o bispo pode usufruir dias melhores, de pleno reconhecimento de sua atuação ou talvez pela "injustiça” cometida pelo Governo Imperial, ao prendê-lo, sujeito à pena com trabalhos forçados, como queria Agnello Bittencourt (1969, p. 140). Alguns anos após a conferência no Paço, ele foi agraciado pelo Governo Imperial com o título de Conde de Belém (1888), tendo sido nomeado Arcebispo da Bahia em 1890, sua província de origem. 


\section{Barbosa Rodrigues e o plano para pacificar e civilizar os índios}

O botânico autodidata João Barbosa Rodrigues (1842-1909) não chegou a concluir o curso de medicina iniciado na Faculdade de Medicina do Rio de Janeiro, não obstante a notoriedade científica alcançada, tendo dirigido o Jardim Botânico de Manaus e, posteriormente, o do Rio de Janeiro. Professor de desenho no Colégio Pedro II, dirigiu-se ao Amazonas em 1872, em nome do Governo Imperial, para realizar estudos científicos, lá permanecendo até 1889. Nomeado diretor do Museu Botânico (1883 a 1889) pelo governo do Amazonas, realizou excursões de pacificação de índios da região. Em 1884, liderou excursões pelo rio Jauapery, pagas pelo governo amazonense, com a missão de pacificar os índios Crichanás. Demitido do cargo pelo primeiro governo republicano amazonense, assumiu a direção do Jardim Botânico do Rio de Janeiro (1889-1908), sua cidade natal.

Embora tenha sido um crítico da exploração e da "guerra de extermínio" dos índios por particulares e por militares enviados pelo governo da Província do Amazonas, e mesmo daqueles que "civilizavam" os índios, levando-os à "decadência", Barbosa Rodrigues não fugiu do roteiro pacificação/catequese/civilização dos índios selvagens, adotado pelas províncias em que grupos indígenas ameaçavam a conquista de territórios de interesse para a colonização. Assim, ao se lançar à exploração do rio Jatapú, o pacificador relatou que havia conseguido dos índios Uassahy (do rio Carimany) a promessa de fazer um descimento, tentativa malograda pela falta de alimentos e transporte. À primeira vista, surpreende o fato de o autor defender a prática de descimento de índios, quando a sua definição do termo reforçava as desvantagens para esses mesmos grupos: ${ }^{9}$

Descer indios ou descimento era o termo outr'ora usado pelos antigos bandeirantes, que para amenisarem as expedições faziam viagens ás malocas, trazendo d'ahi centenas de índios escravizados (Rodrigues, 1885 , p. 5).

A tônica do extermínio dá ao termo uma significação salvadora:

\footnotetext{
${ }^{9}$ A historiografia vem sinalizando para as negociações entre moradores e autoridades e os grupos indígenas quanto aos descimentos na Amazônia colonial, a despeito das estratégias empregadas para obrigar os índios a descerem dos sertões e se instalarem nos aldeamentos. A esse respeito, ver Chambouleyron; Bombardi, 2011, p. 601-623).
} 
Salvar das garras da barbaria centenas de almas que se perdiam no meio das florestas, varridas pelo chumbo que a polvora impellia, sem que até então ninguem tivesse tentado a sua pacificação (Rodrigues, 1885, p. 6).

De forma a evitar-se o contato brutal e imediato com os civilizados, propôs ao presidente o investimento na política de aldeamento, que no período causava muita polêmica. $\mathrm{O}$ aldeamento dos índios deveria seguir uma pedagogia criteriosa: primeiro deixá-los com os seus costumes, para gradativamente os irem abandonando. A educação pelo exemplo, através do assentamento de famílias de agricultores no aldeamento, a catequese e o ensino estavam no rol das "medidas preventivas" que sugeriu ao presidente da província,

[...] afim de poder aproveitar a boa vontade dos indios, tornando-os homens uteis á provincia, evitando que voltem ao estado da barbaria primitiva em que os encontrei, do qual não sahirão senão por meio da bala, como acontecia até março de 1884 [período da 1ạ edição de Crichanás] (Rodrigues, 1885, p. 268).

É interessante observar que o autor via o seu trabalho junto aos índios como uma atividade de catequese, ${ }^{10}$ representação não estranha ao século XIX, quando a catequese empreendida pelos próprios missionários valorizava mais as atividades seculares do que propriamente as religiosas, como, por exemplo, a conversão do gentio ao cristianismo. O ensino da língua portuguesa e das primeiras letras e a indução ao trabalho agrícola e nas oficinas faziam parte da tarefa de catequese e civilização dos índios. O conceito de catequese extrapolava a instrução religiosa, adquirindo uma significação vinculada à imposição da ordem pública e ao desenvolvimento do medo e do respeito às autoridades (Amoroso, 1998).

Barbosa Rodrigues, na sua expedição de pacificação, resgatou e qualificou experiências da pedagogia jesuítica, porém não insistindo na malograda conversão do gentio e sim na sua preservação física para aproveitamento em prol do crescimento econômico da província, ou melhor, a favor da liberação de seu território para a ocupação colonial. A pacificação de índios, enquanto uma técnica específica de coloniza-

\footnotetext{
${ }^{10}$ Quando afirmou, por exemplo, que sem algumas "garantias" a serem tomadas pela presidência, não continuaria na catequese, pois tinha "família numerosa que não quer deixar desamparada por causa de meia duzia de individuos que não trepidam sacrificar a vida do proximo" (Rodrigues, 1885, p. 271).
} 
ção, com uma metodologia de contato própria, fora anteriormente experimentada na região, como um programa do governo colonial, pelo governador do Rio Negro, Lobo d'Almada. Em 1794, o dirigente estabeleceu contatos com os "ferozes e barbaros Tapuyos" (os Mundurucu), "dando-lhes alguns insignificantes mas adequados presentes, de que estes miseráveis muito se satisfazem" (Citado por: Moreira Neto, 1988, p. 117).

Desta forma, o contato amistoso com os índios era uma premissa básica, a ser efetivada pela substituição da pólvora pelos brindes. Assim como Rondon aprimorará nos primórdios do século XX o princípio da não agressão - "morrer se preciso for, matar nunca" ${ }^{11}$ - Rodrigues não recorreu às armas na aproximação aos desconfiados Crichanás, segundo o detalhado relato que fez das três expedições oficiais ao rio Jauapery no ano de 1884. No primeiro encontro com os Crichanás, o então diretor do Museu Botânico relata que: "Recommendei prudencia a todos. Disse ao official que não consentisse que se disparasse uma só arma, salvo quando eu o ordenasse" (Rodrigues, 1885, p. 45).

Em seguida, viu-se "rodeado pelos selvagens que me arrebataram das mãos os brindes". Alguns apresentaram os brindes que lhes deixara na véspera. A comissão utilizou os brindes para desarmar os índios, que traziam "grandes arcos, com gestos e gritos ameaçadores". Só não obteve sucesso com três deles, "os mais furiosos" (Rodrigues, 1885 , p. 46-47). O recebimento de brindes não era fato novo para o grupo: pelo menos uma expedição anterior, contratada pelo governo da província ao vigário de Moura, previu a distribuição de brindes aos índios que ocupavam o rio Jauapery, em 1865. Moradores de Moura também tinham o costume de deixar objetos sem valor na praia, "brindes velhos", como roupas e ferragens, visando adentrar no rio sem sofrerem ataques ou comercializar produtos naturais e artesanais com os índios, principalmente após a sua pacificação. $\mathrm{O}$ autor denuncia que pescarias nem sempre pacíficas foram transformadas em expedições de catequese pelo tenente Horta, o professor de Moura e alguns moradores (Rodrigues, 1885, p. 35)..

Barbosa Rodrigues lamenta os efeitos inesperados da pacificação, como a in-

\footnotetext{
${ }^{11}$ De acordo com Lima (1995), no período do funcionamento do Serviço de Proteção aos Índios, criado em 1910, as pacificações de índios assumiram uma dimensão espetacular em termos políticoadministrativos, construindo-se a imagem de que o Estado garantia a sobrevivência física dos povos pacificados. Muitos povos pacificados e conquistados pelo SPI, reconhecidos hoje como indígenas, na verdade já mantiveram relacionamento com a administração portuguesa e/ou brasileira e também com outras "unidades sociais" antes do contato com os "pacificadores" do Serviço.
} 
tensa exploração comercial dos índios, a ponto de reivindicar ao presidente da província a proibição da circulação de civilizados pelo rio Jauapery, evitando-se assim, não só a exploração, mas também as agressões contra os índios, que ficaram vulneráveis por (supostamente) acreditarem na promessa do naturalista de que os brancos não mais os atacariam. À queixa do grupo de índios inicialmente contatados de que, ao se oporem aos brancos, estes os matavam, "sem que eles atirassem uma só flecha", Rodrigues lhes assegurou "que de ora em diante os brancos não os offenderiam mais" (Rodrigues, 1885 , p. 54). Promessa feita sem qualquer garantia. As notícias sobre os contatos dos índios com os habitantes de Moura, nem sempre pacíficos, levaram-no a uma segunda expedição ao rio, aonde reencontrou índios bastante desconfiados. Uma frase bastante repetida pelos índios, desde o primeiro encontro, foi justamente "Não nos enganem" (Rodrigues, 1885 , p. 51). ${ }^{12}$

Em relação aos índios, Rodrigues se precipitou ao considerar sua missão vitoriosa. Após a primeira expedição, o pacificador teve notícia pelo Vapor Mojú de que os índios se dirigiam a Moura quase diariamente a esperá-lo, trocando armas e diferentes objetos com os moradores. O vapor foi "portador da prova de sua completa pacificação, trazendo centenares de frechas, de arcos e muitos objetos remettidos pelos moradores que os mandavam vender em Manáos" (Rodrigues, 1885, p. 125). Na continuidade do seu extenso relato, o tom recai para a decepção: os moradores dos povoados, alguns ocupando cargos na esfera pública, tais como militares e professores, obtiveram vantagens imediatas facilitadas pela disposição dos índios em incrementar os contatos e as trocas com os civilizados. Na terceira expedição ao rio, o pacificador encontrou "15 embarcações civilisadas, 3 batelões tripulados por mais de 40 indivíduos, grande armamento e muitos arcos, flechas e objetos selvagens". Pertenciam também ao alferes Ferreira da Silva, seu ex-auxiliar, e ao professor público de Carvoeiro. Dias depois, quando encontrou um grupo de índios que o reconhecera, ouviu suas queixas de que "os brancos tinham-Ihe tirado tudo quanto possuiam, deixando-os sem recompensa". Rodrigues os recompensou com machados e outros objetos. Mostrou-se desiludido: "destruiram a obra que me custara tantas fadigas" (Rodrigues, 1885, p. 265267).

\footnotetext{
${ }^{12} \mathrm{O}$ diálogo de Rodrigues com os índios ocorreu com o auxílio de um intérprete, índio que servia sem remuneração a um morador de Moura, que recebeu o pagamento pelo seu trabalho na expedição.
} 
A utilização de brindes para conseguir a "boa vontade" dos índios por parte de particulares recebeu críticas de Rodrigues, alegando que não era meio de amansá-los, "mas sim de tornal-os ladrões e piratas, aguçando-lhes a cubiça" (Rodrigues, 1885, p. 48). Entretanto, todos os seus contatos com o grupo indígena foram intermediados pela entrega de brindes, não só para desarmá-los, mas para adquirir objetos indígenas, levados para o Museu Botânico (Rodrigues, 1886, p. A-22). O naturalista sobrepôs as finalidades científicas (etnografia) e política (pacificar e aldear) à econômica (comercializar). O seu depoimento a respeito do primeiro contato que teve com os Crichanás revela o uso político do brinde: a obediência ao Estado, através de sua pessoa, uma vez que chegou a distribuir brindes em nome do "grande tomini" - "nosso pai", o presidente da província.

[Disse-Ihes] que eu era um branco bom, que os procurara para darIhes presentes, reunil-os em só lugar afim de que os brancos não lhes fizessem mal; que ia fazer roças e casas para elles; que lhes ia dar mais presentes, porém que era preciso obedecer-me, não fazendo mal a mais ninguém (Rodrigues, 1885, p. 51).

Barbosa Rodrigues confiava na (re)instauração de uma política estatal de pacificação, que garantiria à província as riquezas de seu território. A data da conquista dos Crichanás (e de seu território) sem o uso de armas deveria ser lembrada como um acontecimento histórico, uma data célebre simbolizando a paz entre índios e civilizados, compreendida como a restituição de um território que se encontrava sob litígio, conforme pode ser observado na epígrafe deste artigo.

$\mathrm{O}$ autor esclarece que aceitou a comissão, sem ter em vista lucros nem proventos, sem outros interesses. "Meu fim é prestar simplesmente um serviço á humanidade, fiado no estudo que tenho feito do caracter índio" (Rodrigues, 1886, p. 269). 0 naturalista tinha por fim também estudar os "produtos naturais" da região, conhecer a língua dos Crichanás e a geografia do rio Jauapery. ${ }^{13}$ Os resultados, em termos de aquisição de bens simbólicos, podem ser pensados pela divulgação da sua atuação ( $O$ expressar), por meio da publicação do relato de suas expedições, precedido de um histórico dos contatos entre os habitantes de Moura e os grupos indígenas do rio Jau-

\footnotetext{
${ }^{13}$ No apêndice de seu livro, Barbosa Rodrigues apresenta um vocabulário e canto Crichaná, e o plano geográfico do rio Jauapery, levantados por ele em 1884.
} 
apery, que o autorizava a se autodenominar "historiador", e a "exposição pública de tudo que havia obtido dos índios", expondo os seus esforços de etnógrafo e pacificador para um público mais amplo (Rodrigues, 1886, p. 33 e 71). Esforços que não garantiram sua permanência no cargo de diretor do Jardim Botânico de Manaus, projetado por ele: ${ }^{14}$ Rodrigues foi demitido pelo primeiro governador do Amazonas, após a instauração da República. Ao retornar ao Rio, foi imediatamente convidado para dirigir o Jardim Botânico da cidade, tendo alcançado grande notoriedade no cargo. ${ }^{15}$

O pacificador não encontrou o apoio que esperava do governo do Amazonas para a criação do aldeamento. O presidente da província, Ferreira Jr., lamentou não dispor de recursos para aldear os Crichanás, estimados pelo "Diretor do Museu Botânico" em 2.000 indivíduos. O resultado indesejado da pacificação, que indispôs Rodrigues com os moradores de Moura, se manteve em 1885: Ferreira relatou que os índios ainda assustavam os moradores de Moura quando apareciam na povoação em busca de objetos para permutar com os que traziam (Ferreira Junior, 1885, p. 18-19). Não se trata de questionar os êxitos e os fracassos da comissão pacificadora, entretanto, é possível indagar a respeito dos efeitos que ela produziu nas relações de contato entre índios e ocupantes da região.

\section{Conhecer, catequizar e civilizar na construção do homem amazônico: algumas consi- derações finais}

Sob a inspiração do "Orientalismo" de Said (1990), podemos pensar a Amazônia como uma construção histórica, cultural e geográfica, reforçada pelas obras dos autores do século XIX e início do XX: naturalistas, funcionários públicos, eclesiásticos, professores, enfim, intelectuais vinculados a diferentes instituições de produção e divulgação de saberes. É interessante observar que parte destes autores escreveu suas impressões sobre a região e seus habitantes a partir de uma experiência local muito concreta, pois possuía uma "empresa", uma finalidade prática a cumprir. A questão da

\footnotetext{
${ }^{14}$ Na proposta para a criação de um Museu Botânico no Amazonas, apresentada ao presidente da província, Rodrigues incluiu a edição de uma revista para publicação em francês dos estudos históricos, geográficos e etnográficos do museu, de modo a tornar a província conhecida no exterior (Paranaguá, 1883, p. 82)

${ }^{15}$ Entre os seus setenta volumes publicados está o histórico "Jardim Botânico do Rio de Janeiro: uma lembrança do primeiro centenário: 1808 a 1908", 1908. No período em que viveu no Amazonas, escreveu trabalhos sobre a exploração de rios da região, dentre outros (Rocque, 1968).
} 
construção do conhecimento a respeito da população, no caso presente, delimitada à divisão político-territorial referente à Província do Amazonas, instalada em 1852 (Auto..., 1852), é complexa e foi tratada aqui de forma parcial, a partir dos pontos de vista de dois autores que se debruçaram sobre empreendimentos destinados à catequese dos habitantes do interior e à pacificação de índios. Há nas obras destes autores a construção do "homem amazônico" e do índio. Até os migrantes nordestinos e imigrantes foram incorporados à categoria de homens amazônicos, quando descritos como integrados ao modo de vida da região e dedicados à atividade seringueira. Macedo Costa, no seu projeto evangelizador, focalizou o seringueiro, homem chegado às festas, aos "bacanais" e às bebedeiras, o que, além do efeito moral, terminava por acarretar prejuízos econômicos aos patrões, alegações usadas pelo bispo ao tentar angariar o apoio das elites amazonenses para o seu projeto (na conferência realizada em Manaus e na publicação do texto). Contudo, a preocupação com a "catequese dos indígenas" perpassou suas ações e escritos, a começar pela Carta Pastoral referente à sua entrada na Diocese do Pará em 1861 (Carta, 1861. 7 f.).

Não estamos tratando de nenhum "Amazonismo", no sentido proposto por Said, mesmo porque a Amazônia não parecia constituir um campo estruturado de estudos. O pragmatismo dos viajantes e de suas funções fazia com que jamais se esquivassem de propor soluções, invariavelmente dirigidas para a colonização de territórios e a civilização e a catequese de sua população. A preocupação que os colonizadores britânicos tiveram em conhecer a Índia, sua cultura, história, religião e principalmente, o seu povo, sem esquecer da importância dada aos achados arqueológicos e à constituição de acervos para os museus europeus, desenvolvendo métodos sofisticados de pesquisa, identificação e classificação da população (Cohn, 1996), não é observada no caso da Amazônia, ao menos, como uma política sistemática de Estado.

Embora os autores buscassem conhecer de perto os problemas da região, o que implicou na descrição e na interpretação do observado, o objetivo era alcançar fins práticos e não científicos. Os resultados em termos da aquisição de bens simbólicos, como prestígio, acesso a cargos e pensões, publicações de relatos e coleta de objetos indígenas para compor as coleções dos museus não devem ser desprezados. Oliveira Filho ressalta que as observações etnográficas dos naturalistas viajantes devem ser entendidas como frutos do emprego de categorias de análise e de procedimentos 
de construção dos objetos de conhecimento disponíveis na época (Oliveira Filho, 1980, p. 38). Os seus discursos são construídos a partir de um repertório de teorias e representações acessíveis pela formação acadêmica e pela circulação de informações (livros, periódicos científicos, artigos em jornais, conferências e exposições de material etnográfico). Pelas funções que exercia, Barbosa Rodrigues certamente estava a par das discussões e dos resultados das observações dos naturalistas a respeito dos índios do Brasil. Mas é certo que Macedo Costa não se descuidou desse conhecimento ao acompanhar os debates dos grupos intelectuais empenhados em pensar a construção da nacionalidade.

As representações sobre o índio amazônico neste período, visto, ora como decadente, ora como um ser primitivo, porém, sempre na infância da vida, sem dúvida contribuíram para que autores, nacionais e estrangeiros, não percebessem a complexidade e a diversidade das culturas ali presentes. A resistência de grupos indígenas que fugiam da expansão colonial, embrenhando-se nas matas, dificultava a localização das tribos selvagens por parte das expedições ${ }^{16}$, reforçando a forte crença na degeneração do índio e na decadência de vários aspectos de sua vida. É certo que nesse período, a "ideologia" da decadência era igualmente referida ao oriental, mas neste caso, o colonizador dispunha da nobre justificativa de "restaurar uma região, da sua barbárie presente, à sua antiga grandeza clássica" (Said, 1990, p. 94).

As tarefas assumidas pelos viajantes visavam, em última análise, conhecer e atuar sobre o modo de vida das populações amazônicas, de forma a subsidiar planos imediatos de colonização dos territórios e catequese dos seus habitantes. A despeito do discurso corrente na época da degeneração do índio e da sua condição primitiva, pairava a respeito das várias etnias das quais tinha-se conhecimento ou contato, a ameaça da revolta e das "correrias de índios", sob a sombra da Cabanagem. O surgimento dos Cristos do rio Negro e de outros rios, envolvendo comunidades de índios e de tapuios, resultou em respostas rápidas do governo da província em termos de re-

\footnotetext{
${ }^{16}$ Foi a custo de muitos brindes e da busca de "indícios de tribos" pela mata que Barbosa Rodrigues conseguiu encontrar o primeiro grupo de Crichanás com quem teve contato. Após dias de procura, acabou sendo "achado" por um grupo de 40 índios, quando parara para secar os brindes que haviam molhado. Um fator que o naturalista considerou fundamental para a aproximação foi a ausência de um morador de Moura que integrava a expedição, "patrão" do índio intérprete, e que já tivera contatos com os índios, no que ele chamava de "expedições de catequese", na verdade contatos nem sempre pacíficos, intermediados por brindes (Rodrigues, 1885, p. 45).
} 
pressão aos movimentos (Moreira Neto, 1988). Embora houvesse diferenças importantes em termos da formação dos autores e dos objetivos de suas missões, a crença na possibilidade de catequese e civilização dos índios perpassa os seus textos. A preocupação central dos autores retratados não é com a questão racial - se a raça americana é degenerada ou se a solução é a mestiçagem com o branco. Ambos acreditavam na eliminação do estado selvagem dos índios e a sua inevitável incorporação à civilização, considerando, inclusive, ser necessária a intervenção do Estado nesse sentido. A comparação do índio a uma criança, explicitada por Barbosa Rodrigues, permitiu aos autores proporem medidas para a sua educação para a vida civilizada. A comparação do índio à criança é também associada à sua aproximação ao mundo da natureza, o homem natural em oposição ao social. Assim se expressou Barbosa Rodrigues com relação ao tema:

O indio é uma criança. Não a maltratem, que ella não offenderá pessoa alguma. Si a traição e a ingratidão são o apanagio de alguns, estude-se a sua historia e ver-se-ha que estes foram leaes e fieis, mais que a oppressão depois os transformou. 0 proprio animal não esquece as offensas recebidas (Rodrigues, 1885, p. 56. Grifo nosso).

Apesar do projeto de D. Macedo Costa não tratar especificamente dos índios, mas de um genérico "homem amazônico", ele reconheceu a influência dos costumes indígenas sobre essa população, os quais queria ver sanados. ${ }^{17} \mathrm{Um}$ bispo comprometido com a reforma social, abalizado nas observações dos costumes dos povos do Amazonas, e um naturalista e diretor de uma instituição destinada a colecionar produtos naturais e artefatos etnográficos dos grupos indígenas, ambos com experiência de atuação no magistério, dedicaram-se a promover a catequese e a civilização das populações da região. Em comum, a crença na capacidade de integração dos nativos no porvir do imenso vale, todavia, incorporados à "comunhão política do império", como bem ressaltou Macedo Costa. O projeto consensual dos poderes locais, representados pela presidência da província e pela diocese, aliados ao poder central do Império, era o de manter a unidade da nação. A resistência das "tribos selvagens" a uma integração ao custo da perda da identidade étnica é reconhecida pelos autores, contudo,

\footnotetext{
${ }^{17}$ Na parte inicial de seu projeto em que apresenta um relato histórico do trabalho dos missionários no Amazonas, Macedo Costa afirma que "o selvagem não é o homem primitivo, é o homem degenerado". A degeneração para ele é de cunho moral, resultando da degradação do caráter (Costa, 1884, p. 27).
} 
inserida no registro da selvageria, da ferocidade e do apego irracional aos seus hábitos e tradições, incitando particulares, religiosos e o poder público a encetarem ações de catequese, simbólica e, por vezes, literalmente violentas.

\section{Referências}

ALMEIDA, Alfredo Wagner Berno de. A crise da lavoura maranhense no último quartel do século XIX. Projeto de pesquisa. In: Projeto Emprego e Mudança Sócio Econômica no Nordeste. Rio de Janeiro: Museu Nacional/PPGAS/UFRJ, 1977.

ALMEIDA, José Ricardo de. História da instrução pública no Brasil (1500-1889): história e legislação. São Paulo: EDUC; Brasília: INEP, MEC, 1989. (1 ${ }^{a}$ ed. 1889).

ALVES, Márcia Eliane. Educação, trabalho e dominação. Casa dos Educandos Artífices: 1858-1877. In: Amazônia em Cadernos. História em Novos Cenários. Manaus: Universidade do Amazonas/Museu Histórico, 91-105, v.2, n. 2/3 de dez. de 1993/94, 1995.

AMOROSO, Marta Rosa. Catequese e evasão: etnografia do aldeamento indígena São Pedro de Alcântara, Paraná (1855-1895). Tese (Doutorado em Antropologia) - São Paulo, USP, 1998.

AZAMBUJA, Joaquim Maria Nascentes de. Doutrinas pedagógicas e elementos de instrucção publica organisadas pelo Conselheiro D'Azambuja para uso das escolas de ensino primario especialmente das Províncias do Amazonas e do Pará. Pará: Typ. do Livro do Commercio, s.d. [1884].

AUTO da Installação da Provincia do Amazonas pelo Exmo Srn. João Baptista de Figuereido Tenreiro Aranha, seu primeiro presidente, no dia 10 de janeiro de 1852. Amazonas: Typ. de M. da S. Ramos, 1852.

BITTENCOURT, Agnello. Dicionário amazonense de biografias. Rio de Janeiro: Artenova, 1969.

CARTA Pastoral do Bispo do Pará, d. Antonio de Macedo Costa, por ocasiao da sua entrada na Diocese. Pará: Typ de Santos \& Irmaos, 1861. 7 f. (Arquivo Nacional - Coleção Eclesiástica - Pará).

CHAMBOULEYRON, Rafael; BOMBARDI, Fernanda Aires. Descimentos privados de índios na Amazônia colonial (séculos XVII e XVIII). Varia História, Belo Horizonte, v.27, n.46, p.601-623, dez. 2011.

COHN, Bernard S. Colonialism and its forms of knowledge: the British in India. Princeton, New Jersey: Princeton University Press, 1996.

COSTA, Antonio de Macedo. A Amazonia: meio de desenvolver a sua civilisação. Conferencia recitada em Manaus, no Paço da Assembleia Provincial, perante o Exmo Sr. Presidente da Provincia e grande número de pessoas gradas, no dia 21/3/1883. $3^{a}$ ed., Rio de Janeiro: Typ. de G. Leuzinger \& Filhos, 1884.

COSTA, Antonio de Macedo. Discurso pronunciado pelo Excellentissimo Senhor D. Antonio de Macedo Costa, Bispo do Pará, na solenne Inaurguração da Bibliotheca Publica fundada na mesma Provincia no dia 25 de março de 1871. Pará: Typ. do "Diario do Gram-Pará, 1871. 16 p. (Ed. fac-similada da Academia Paraense de Letras, 1978).

COSTA, Hideraldo Lima da. Cultura, trabalho e luta social na Amazônia: discurso dos viajantes - século XIX São Paulo: PUC-SP, 1995 (História, Dissertação de Mestrado), p. 188. 
ELIAS, Norbert. O processo civilizador. Rio de Janeiro: Jorge Zahar, v.1 e 2, 1993/1994. FERREIRA JUNIOR, José Jansen. Falla que o exm. sr. dr. José Jansen Ferreira Junior, presidente da provincia do Amazonas, dirigiu á Assembléa Legislativa Provincial, por occasião da installação da 2.a sessão da 17.a Legislatura, em 25 de março de 1885. Manáos: Typ. do Amazonas, 1885, p. 18-19. <http://brazil.crl.edu/bsd/bsd/97/>

LIMA, Antônio Carlos de Souza. Um grande cerco de paz: poder tutelar, indianidade e formação de Estado no Brasil. Petrópolis: Vozes, 1995.

LUSTOSA, Antonio de Almeida. Dom Macedo Costa: Bispo do Pará. Rio de Janeiro: Cruzada da Boa Imprensa, 1939.

MARTINS, Karla Denise. O Sol e a Lua em tempo de eclipse: a reforma católica e as questões políticas na Província do Grão-Pará (1863-1878). Dissertação (Mestrado em História) - Campinas, SP, IFCH/UNICAMP, 2001.

MARTINS, Karla Denise. Cristóforo e romanização do inferno verde: as propostas de D. Macedo Costa para a civilização da Amazônia (1860-1890). Tese (Doutorado em História) - Campinas, SP: IFCH/UNICAMP, 2005.

MARTINS, Karla Denise. A "civilização cristã" como projeto católico para a sociedade amazônica: Amazônico D. Macedo Costa e seus interlocutores no oitocentos. Revista Tempo Amazônico, v. 2, n.2, p. 141-169, jan-jun de 2015.

MOREIRA NETO, Carlos de Araújo. Índios da Amazônia: de maioria a minoria (17501850). Petrópolis: Vozes, 1988, p. 117.

OLIVEIRA FILHO, João Pacheco. O caboclo e o brabo: notas sobre duas modalidades de força-de-trabalho na expansão da fronteira amazônica no século XIX. Encontros com a civilização brasileira, n. 11. Rio de Janeiro: Civilização Brasileira, 1979.

OLIVEIRA FILHO, João Pacheco. Os atalhos da magia: reflexões sobre o relato dos naturalistas viajantes na etnografia indígena. Rio de Janeiro: Museu Nacional/ PPGAS/UFRJ, maio de 1980. Mimeo.

OLIVEIRA FILHO, João Pacheco. Elementos para uma sociologia dos viajantes. In: Sociedades indígenas e indigenismo no Brasil. UFRJ: Marco Zero, 1987.

PARANAGUÁ, José Lustosa da Cunha. Relatorio apresentado á Assembléa Legislativa Provincial do Amazonas na abertura da segunda sessão da decima sexta legislatura em 25 de março de 1883 pelo presidente José Lustosa da Cunha Paranaguá. Manáos: Typ. do Amazonas, 1883, p. 45. <http://brazil.crl.edu/bsd/bsd/94/>

PARANAGUÁ, José Lustosa da Cunha. Relatorio apresentado á Assembléa Legislativa, 1883, p. 82. <http://brazil.crl.edu/bsd/bsd/94/>

RIZZINI, Irma. Tese (Doutorado em História). O cidadão polido e o selvagem bruto: a educação dos meninos desvalidos na Amazônia Imperial. Rio de Janeiro: UFRJ/IFCS/PPGHIS, 2004.

RIZZINI, Irma. Educação popular na Amazônia Imperial: crianças índias nos internatos para formação de artífices. In: SAMPAIO, Patrícia; ERTHAL, Regina (Orgs). Rastros da memória: histórias e trajetórias das populações indígenas na Amazônia. Manaus: EDUA/CNPq, p. 133-171, 2006.

RODRIGUES, João Barbosa. Pacificação dos Crichanás. Rio de Janeiro: Imprensa Nacional, 1885.

RODRIGUES, João Barbosa. Museu Botanico do Amazonas, 6 de fevereiro de 1886. In: CHAVES, Ernesto Adolpho de Vasconcellos. Relatorio com que o exm. sr. dr. Ernesto Adolpho de Vasconcellos Chaves, presidente da provincia do Amazonas, installou a 1.a sessão da 18.a legislatura da Assembléa Legislativa Provincial no dia 25 de março de 
1886. Anexo n. 15. Manáos: Typ. do Jornal do Amazonas, 1886, p. A-22. <http://brazil.crl.edu/bsd/bsd/98/000065.html>

ROCQUE, Carlos. Grande Enciclopédia da Amazônia. Manaus: AMEL, 1968.

SAID, Edward W. Orientalismo: o Oriente como invenção do Ocidente. São Paulo: Companhia das Letras, 1990.

SAMPAIO, Patrícia Maria Melo. Os fios de Ariadne: tipologia de fortunas e hierarquias sociais em Manaus: 1840-1880. Manaus: Editora da Universidade do Amazonas, 1997. SILVA, Aracy Lopes; GRUPIONI, Luís Donisete (org.). A temática indígena na escola: novos subsídios para professores de $1^{\circ}$ e $2^{\circ}$ graus. Brasília, MEC/MARI/UNESCO, 1995. WEINSTEIN, Barbara. A borracha na Amazônia: expansão e decadência (1850-1920). São Paulo: HUCITEC, EDUSP, 1993, p. 29 e 39.

Artigo recebido em setembro de 2018 e aceito em novembro de 2018. 